\title{
The role of Mycobacterium tuberculosis lineages on lung tissue damage and TNF-a level among tuberculosis patients, Indonesia by Ni Made Mertaniasih
}

Submission date: 28-Nov-2019 09:07PM (UTC+0800)

Submission ID: 1223267711

File name: amage_and_TNF-a_level_among_tuberculosis_patients,_Indonesia.pdf (420.42K) Word count: 4539

Character count: 23492 


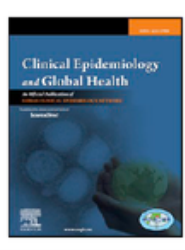

\title{
The role of Mycobacterium tuberculosis lineages on lung tissue damage and TNF- $\alpha$ level among tuberculosis patients, Indonesia
}

\author{
Muhammad Amin ${ }^{\mathrm{a}, \mathrm{b}, \mathrm{c}}$, Budi Yanti ${ }^{\mathrm{d}, *}$, Harapan $\operatorname{Harapan}^{\mathrm{e}}$, Ni Made Mertaniasih ${ }^{\mathrm{f}, \mathrm{g}}$ \\ "Department of Pulmonology and Medical Respirology, Faculty of Medicine, Airlangga University, Surabaya, Indonesia \\ ${ }^{b}$ Airlangga University Hospital, Surabaya, Indonesia \\ 'Dr. Soetomo Academic Medical Center Hospital, Surabaya, Indonesia \\ ${ }^{\mathrm{d}}$ Department of Pulmonology and Medical Respirology, School of Medicine, Syiah Kuala University, Banda Aceh, Indonesia \\ 'Medical Research Unit, School of Medicine, Syiah Kuala University, Banda Aceh, Indonesia \\ 'Department of Medical Microbiology, Faculty of Medicine, Airlangga University, Surabaya, Indonesia \\ ${ }^{8}$ Institute of Tropical Disease, Airlangga University, Surabaya, Indonesia
}

\section{A R T I C LE I N F O}

\section{Keywords:}

Tuberculosis

Mycobacterium tuberculosis

Lineage

Strain

Severity

\begin{abstract}
A B S T R A C T
Background: Mycobacterium tuberculosis (MTB) is divided into ancient and modern lineage. Both lineages have different virulence property and therefore associated with different immune responses and disease severity in tuberculosis (TB) patients. The aim of this study was to determine the association between MTB lineages and the level of tumor necrosis factor alpha (TNF- $\alpha$ ), and lung tissue damage among Indonesian TB patients.

Methods: Thirty new and active TB patients were recruited randomly from Dr. Soewandhie Hospital, Surabaya, Indonesia. MTB isolates were isolated from bronchoalveolar lavage fluid (BALF) and their lineages were determined by primer-specific PCR targeting TbD1 and $R D 9$ region gene. The degree of lung tissue damage was assessed and classified using NICE Scoring System and TNF- $\alpha$ level of BALF was measured by ELISA.

Results: MTB were detected in all patients in which 17 and 13 isolates were classified as modern and ancient lineage, respectively. Modern lineage was associated with the degree of lung damage (odds ratio [OR]: 3.97 ; 95\% CI: $1.57-6.37), p<0.001)$. This lineage was also associated with high TNF- $\alpha$ level (OR: 2.06 ; $95 \% \mathrm{CI}$ : $1.31-47.00, p=0.026$ ). In addition, the level of TNF- $\alpha$ was higher in severe compared to mild lung damage cases $(p=0.001)$.

Conclusion: Modern lineage is likely associated with high TNF- $\alpha$ level and increases the risk of having severe lung damage three times among TB patients from Indonesia. Therefore, laboratory test to determine MTB lineages might crucial to be integrated in National Tuberculosis Control Program in the country.
\end{abstract}

\section{Introduction}

It is estimated that one million of new tuberculosis (TB) cases occur annually in Indonesia, the second rank of the highest TB cases after India. ${ }^{1}$ In 2015, the World Health Organization (WHO) estimated there were 10.4 million new TB cases, but only 6.1 million cases were detected and officially notified. ${ }^{2}$ This highlights a large gap in locating and detecting people who may be infected with TB. Tuberculosis still remains to be one of the leading cause of morbidity associated with lung tissue damage throughout the world. ${ }^{3}$ The deterioration in public health systems in developing countries, and the emergence of multidrug resistance forms of TB also contribute to TB spread. ${ }^{20}$

Over 2 billion people are believed to harbor latent Mycobacterium tuberculosis complex (MTBC), the causative agent of TB. Mycobacterium tuberculosis complex comprises of Mycobacterium tuberculosis (MTB), M. africanum, $M$. canettii, $M$. bovis, $M$. microti, $M$. orygis, $M$. caprae, $M$. pinnipedii, $M$. suricattae and $M$. mungi. ${ }^{5}$ One of the first evolution reconstruction on MTBC genetic structure is known as a TbD1 region deletion. $T b D 1$ deletion strain is referred as modern lineage while strain without deletion known as the ancestral or ancient lineage. ${ }^{6,7}$ The impact of strain diversity in human TB has been well established increasingly in various infection models. A particular lineage consists of different molecular, cellular, immunological, epidemiological virulence and global pyelography. ${ }^{6,8}$ It is well know that the modern lineage is associated with more virulent with rapid disease progression, extensive lung tissue damage, drug resistance, produced high proinflammatory

\footnotetext{
Aceh 23111, Indonesia.

E-mail address: byantipulmonologis@unsyiah.ac.id (B. Yanti).

https://doi.org/10.1016/j.cegh.2018.11.002

Received 6 June 2018; Received in revised form 26 October 2018; Accepted 5 November 2018

Available online 07 November 2018

2213-3984/ (C) 2018 Published by Elsevier, a division of RELX India, Pvt. Ltd on behalf of INDIACLEN.
}

- Corresponding author. Department of Pulmonology and Medical Respirology, School of Medicine, Syiah Kuala University, Jl. T. Tanoeh Abe, Darussalam, Banda 
citokynes and outbreak rates. ${ }^{9-12}$

Tumor necrosis factor alpha (TNF- $\alpha$ ) is a pleiotropic cytokine with nonredundant roles in TB and perturbations of TNF- $\alpha$ levels significantly affect the course of infection. In disease progressive, TNF- $\alpha$ is associated with disease activity which able to upregulate metalloproteinases and therefore facilitates degradation of structural lung structure. ${ }^{3}$ TNF- $\alpha$ also contributes to the formation of granulomas, infection control, driven necrosis and cavity that resulting subsequent tissue destruction. ${ }^{9,13,14}$ Study assessing the level of TNF- $\alpha$ in bronchoalveolar lavage fluid (BALF) in active pulmonary TB patients is limited. It is believed that the modern lineage is associated with high proinflammatory citokynes ${ }^{10-12}$ and studies also demonstrated that TNF- $\alpha$ level significantly higher in BALF of active pulmonary TB patients. ${ }^{15,16}$ However, in-vitro, studies found that high virulence of MTB lineages such as modern lineage were associated a low inflammatory response. ${ }^{17,18}$ Low level of inflammatory cytokine was also demonstrated for MTB HN878 strain infection, a member of Beijing family of modern lineage, which became an outbreak in Texas. ${ }^{19}$ Studies using different types of cell lines also found that modern lineage induced lower TNF- $\alpha$ level than those of ancient lineage in-vitro. ${ }^{20-23}$ Therefore, more study to assess the association between MTB lineages and TNF- $\alpha$ level is required. This aim of this study was to assess the association between MTB lineages and both of lung tissue damage and the level of TNF- $\alpha$ among $\mathrm{TB}$ patients in Indonesia.

\section{Methods}

\subsection{Ethical consideration}

The protocol of this study was approved by Ethical Committee of Health Research Dr. Soetomo Academic Medical Center Hospital (No: 388/PANKE/KKE/V/2017). The work was carried out in accordance with the Code of Ethics of the World Medical Association for experiments involving humans. Informed consent was obtained from all participants prior to enrolment.

\subsection{Study setting}

A cross-sectional study was conducted at Dr. Soewandhie Hospital, Surabaya, Indonesia, between June and October 2017. A consecutive sampling method was employed to recruit the patients. All new and active TB patients were invited to participate and once they agreed and met the inclusion criteria, the patients were prepared for the bronchoalveolar lavage (BAL) procedure. To perform a BAL, the patients must met certain conditions: Cardiac Risk Index $=1, \mathrm{PO}_{2}$ more than $65 \mathrm{mmHg}$ without oxygen supply, no breathlessness, hemoglobin more than $10 \mathrm{~g} / \mathrm{dl}$, and classified as American Society of Anesthesiologists Classification (ASA) level I anesthesia.

\subsection{Patients}

All new and active TB cases, diagnosed based on combination of sputum acid fast bacilli (AFB) staining, chest radiograph, and Xpert MTB/RIF assay (Cepheid, Sunnyvale, CA, United States), and aged 15-60-years-old were recruited. Ziehl-Neelsen AFB staining and the result interpretation were conducted based on International Union Against Tuberculosis (IUALTD) recommendation ${ }^{24}$ and the interpretation of chest radiograph was performed by two radiologists independently. Patients with HIV, diabetes mellitus, abnormal renal function, heart diseases, immune response disorders such as systemic lupus erythematosus and rheumatoid arthritis, and non-TB pulmonary diseases were excluded.

\subsection{Detection of MTB lineages}

Detection of MTB lineages was conducted to BALF. Bacterial genetic
Table 1

Primers used to amplify RD9 and TbD1 gene region of MTB.

\begin{tabular}{llc}
\hline Region Primers name & \multicolumn{1}{c}{ Sequences } & Amplicon (bp) \\
\hline RD9 & 8 & 306 \\
Forward & 5'-GTG-TAG-GTC-AGC-CCC-ATC-C-3' & \\
RD9 Int & 5'-CAA-TGT-TTG-TTG-CGC-TGC-3 & \\
Reverse & 5'-GCT-ACC-CTC-GAC-CAA-GTG-TT-3' & \\
TbD1 & & 580 \\
$\quad$ Forward & 5'-AGTGACTGGCCTGGTCAAAC-3' & \\
Reverse & 5'-GAGCTCTGTGCGACGTTATG-3' & \\
\hline
\end{tabular}

material were extracted using DAeasy ${ }^{*}$ Blood \& Tissue kit (Ambion, Inc., Austin, TX, USA) according to the manufacturer's instructions. To identify the modern and ancient lineage, primer-specific PCRs targeting $R D 9$ and $T b D 1$ gene region of MTB genome were conducted. $R D 9$ regions present in both of modern lineage and ancient MTB lineage while $T b D 1$ present in ancient lineage and absent in modern lineage. ${ }^{7,25}$ The primers for $R D 9$ and $T b D 1$ are presented in Table 1.

\subsection{Assessment of lung damage}

The degree of pulmonary damage was classified using the NICE Scoring System based on the total lesions in six lung areas. ${ }^{26}$ This scoring system assesses four components: nodule $(\mathrm{N})$, infiltration or consolidation (I), cavity (C) and ectasis (E) based on chest radiograph of three areas of each lung (i.e. six areas of both lungs). For each area, the score was 1-4 indicating lung damage area of $0-25 \%,>25 \%$ - $\leq$ $50 \%,>50 \%-\leq 75 \%$ and $>75 \%$, respectively. The pulmonary damage was categorized as mild if the total score was 8 or less and severe if the total score was more than 8 .

\subsection{TNF- $\alpha$ measurement}

The level of TNF- $\alpha$ from BALF supernatant were measured with a solid phase sandwich enzyme-linked immunosorbent assay (ELISA) using microtitre plates from LEGEND MAX ${ }^{\mathrm{m}}$ Human TNF-a ELISA Kit (BioLegend, San Diego, CA, USA) following manufacturer's protocol.

\subsection{Statistical analysis}

We did explorative statistical analyses to assess the potential variables of patient characteristics associated with lineages of MTB and lung damage. The associations between [patient characteristics] and [MTB lineages, lung damage and TNF- $\alpha$ level] were assessed using chisquared test. For statistical analysis, TNF- $\alpha$ divided into two categories, low and high, in which low if value less than $1167 \mathrm{pg} / \mathrm{ml}$ and high if equal or higher than $1167 \mathrm{pg} / \mathrm{ml}$. Chi-squared test was also used to assess the association between [MTB lineages] and [the degree of lung damage and TNF- $\alpha$ level]. For all analyses, significance was assessed at $\alpha=0.05$. Statistical Package of Social Sciences 18.0 software (IBM Inc., Chicago, IL, USA) was used to analyze the data.

\section{Result}

\subsection{Patients' demographics and clinical characteristics}

Between June and October 2017, 30 new TB cases were included in the study. Majority of the patients $(56.7 \%)$ were female and a third of the patients aged between 21 and 30 years old (Table 2). Among 30 cases, $12(40.0 \%)$ were AFB smear-positive sputum. Infiltrate was detected in all cases while only one case had lung cavity. The Xpert MTB/ RIF assay confirmed MTB in $25(83.3 \%)$ cases. Five $(16.7 \%)$ negative patients, based on Xpert MTB/RIF assay, were also included in the final analysis because all of them had positive sputum AFB staining and chest $\mathrm{X}$-ray with tuberculosis lesion. This is in accordance with the Infectious 
Table 2

Patients' demographics and clinical characteristics.

\begin{tabular}{|c|c|c|}
\hline Characteristics & $\mathbf{n}$ & (\%) \\
\hline \multicolumn{3}{|l|}{ Gender } \\
\hline Female & 16 & 53.3 \\
\hline Male & 14 & 46.7 \\
\hline \multicolumn{3}{|l|}{ Age (year) } \\
\hline Less than 21 & 5 & 16.7 \\
\hline $21-30$ & 10 & 33.3 \\
\hline 31.40 & 5 & 16.7 \\
\hline $41-50$ & 6 & 20.0 \\
\hline More than 50 & 4 & 13.3 \\
\hline \multicolumn{3}{|l|}{ Educational attainment } \\
\hline Elementary school & 8 & 26.7 \\
\hline Junior high school & 14 & 46.7 \\
\hline Senior high school & 8 & 26.7 \\
\hline \multicolumn{3}{|c|}{ Sputum acid-fast staining } \\
\hline Negative & 18 & 60.0 \\
\hline Positive & 12 & 40.0 \\
\hline \multicolumn{3}{|l|}{ NICE Score } \\
\hline \multicolumn{3}{|l|}{ Nodul } \\
\hline Yes & 22 & 73.3 \\
\hline No & 8 & 26.7 \\
\hline \multicolumn{3}{|c|}{ Infiltrator or consolidation } \\
\hline Yes & 30 & 100.0 \\
\hline No & 0 & 0.0 \\
\hline \multicolumn{3}{|l|}{ Cavitas } \\
\hline Yes & 1 & 3.3 \\
\hline No & 29 & 96.7 \\
\hline \multicolumn{3}{|l|}{ Ectasis } \\
\hline Yes & 27 & 90.0 \\
\hline No & 3 & 10.0 \\
\hline \multicolumn{3}{|l|}{ Lung damage } \\
\hline Mild & 11 & 36.7 \\
\hline Severe & 19 & 63.3 \\
\hline \multicolumn{3}{|l|}{ TNF- $\alpha$ level } \\
\hline Low & 18 & 60.0 \\
\hline High & 12 & 40.0 \\
\hline \multicolumn{3}{|l|}{ Xpert ultra assay } \\
\hline Positif & 25 & 83.3 \\
\hline Negatif & 5 & 16.7 \\
\hline
\end{tabular}

Disease Society of America (IDSA) and WHO guidelines. ${ }^{27-29}$ Ninety percent of the patients presented lung ectasis. Out of total cases, 19 $(63.3 \%)$ had severe lung damage based on NICE Scoring System and 18 $(60.0 \%)$ had low TNF- $\alpha$ level (Table 2 ).

\subsection{Mycobacterium tuberculosis lineages}

Out of 30 MTB isolates, based on RD9 and TbD1 region detection, we identified $13(43.4 \%)$ isolates as ancient lineage $(T b D 1+$ and $R D 9+)$ and $17(56.7 \%)$ as modern lineage (TbD1-) (RD9+).

\subsection{Association between patients' characteristics and Mycobacterium} tuberculosis lineage, lung damage, and TNF- $\alpha$ level

There was no association between the patients' characteristics (age, gender, educational attainment, and AFB staining of sputum) and MTB lineages (Table 3). We also found that patients' characteristics and AFB smear had no association for both lung damage and TNF- $\alpha$ level (Table 3).

3.4. Association of Mycobacterium tuberculosis lineage on lung damage and TNF- $\alpha$

Modern lineage was identified among $16(84.2 \%)$ patients with severe lung damage while ancient lineage was identified in 10 out of 11 (90.9\%) of mild lung damage cases. There was a significant association between modern lineage and severe lung parenchymal damage, $\mathrm{OR}=3.97$; CI 95\%: 1.57-6.37, $p<0.001$ ) (Table 4). There was a significant association between MTB lineage and TNF- $\alpha$ level, in which modern lineage associated with higher TNF- $\alpha$ level $(\mathrm{OR}=2.06$; CI 95\%: $1.31-47.00$ with $p=0.026$ ). We also found that the level of TNF$\alpha$ was higher among patients with severe lung damage compared to those with mild lung damage $(1359.1 \pm 462.9 \mathrm{pg} / \mathrm{ml}$ vs. $760.8 \pm 471.3 \mathrm{pg} / \mathrm{ml}(p=0.001$, analyzed with Mann-Whitney Test).

\section{Discussion}

We found that modern lineage is more prevalent among TB cases. This result is comparable with another study in Indonesia that found Beijing genotype family (member of modern lineage) was more prevalent in populous region in Indonesia. ${ }^{30}$ Our study site, Surabaya, is the second largest city in Indonesia after Jakarta, with a land area of $333,063 \mathrm{~km}^{2}$ and a population of more than 3 million. Surabaya is a center for business, trade, industry and education in eastern Java. In the context of other countries, a study in North India in 2014 found that $81.1 \%$ of $\mathrm{TB}$ cases were associated with modern lineage. ${ }^{31}$ Another study in eastern and western regions of Azerbaijan also found that the prevalence of modern lineage in western Azerbaijan was higher than in eastern Azerbaijan because western region is the borderland of Iran with a higher population movement from neighboring countries. ${ }^{32} \mathrm{Al}$ together, these data indicate that MTB lineages are distributed differently in geographical regions and their distributions are related to population migratory. ${ }^{33}$

We found a significant association between modern lineage and severe lung damage and a high level of TNF- $\alpha$. It is well known that MTB modern lineage is more virulent than ancient lineage. ${ }^{12,34,35} \mathrm{Al}$ though, the genomic sequence of MTB modern lineage, such as the H37Rv strain, is $99.95 \%$ identical with the $M$. bovis, ancient lineage, ${ }^{36}$ there are some virulent properties that associated with lung tissue damage among modern lineage. ${ }^{37}$ This might associate with virulence property of MTB lineages that links to diversity of lipid and protein composition and secretion. The composition of cell wall lipid (phthiocerol dimycocerosate, lipomannan, lipoarabinomannan, trehalose dimycolate) is highly conserved within a lineage and this associated with induction of proinflammatory cytokines and granuloma formation. ${ }^{38}$ Lipomannan from virulent MTB lineage binds Toll-like receptor 2 (TLR2) in the surface of macrophage to produce proinflammatory cytokines such as TNF- $\alpha .{ }^{13}$ As a consequence, TNF- $\alpha$ upregulates matrix metallopeptidase 9 expression, a family member of proteases that are collectively able to degrade extracellular pulmonary matrix. Another MTB virulence that contributes to granuloma formation is the $6 \mathrm{kDa}$ early secretory antigenic target (ESAT6). This protein, a member of the ESX-1 family, plays a critical role for recruitment of macrophages to form granulomas and granuloma expansion. ${ }^{9}$ ESAT6 independently induces TNF- $\alpha$ release and subsequent induces matrix metallopeptidase 9.,38 Taken together, TNF- $\alpha$ might potentiate tissue destruction in multiple ways during TB infection. ${ }^{13}$

High virulence of modern lineage might also influenced by another cell wall component: sulfolipid-1. Sulfolipid-1 is one of the most abundant lipids in the mycobacterial outer membrane and its production is higher in modern lineage than ancient lineage. ${ }^{39}$ High production of sulfolipid-1 in modern lineage is associated with reduction of phagocytosis macrophage ability. ${ }^{39}$ Ancient lineage also lacks of trehalose-containing glycolipids in its cell wall. ${ }^{40}$ This loss represses to PhoPR signalling system and reduces biosynthesis of cell-wall complex lipids and Esx/ESAT-6 secretion. As a sequence, this reduces immunogenicity and virulence of the ancient lineage. Altogether, these indicate that modern lineage is more virulent and therefore is associated with more severe disease including lung tissue damage. ${ }^{40}$

This study has several limitations. This study was conducted at a single center and small number of patients and; therefore, it is not representative of current TB condition in Indonesian due to referral bias. This study did not include all consecutive patients who were diagnosed with active pulmonary TB because not all of patients were willing to follow the intervention measures undertaken in this study. Finally, 
Table 3

The association between patient characteristics and Mycobacterium tuberculosis lineage, lung damage and tumor necrosis factor- $\alpha$ level.

\begin{tabular}{|c|c|c|c|c|c|c|c|c|c|c|}
\hline \multirow[t]{2}{*}{ Characteristics } & \multirow[t]{2}{*}{$\mathrm{n}$} & \multicolumn{2}{|l|}{ MTB lineage } & \multirow[t]{2}{*}{$p$-value } & \multicolumn{2}{|c|}{ Lung damage } & \multirow[t]{2}{*}{$p$-value } & \multicolumn{2}{|l|}{ TNF- $\alpha$ level } & \multirow[t]{2}{*}{$p$-value } \\
\hline & & Ancient n (\%) & Modern n (\%) & & Mild n (\%) & Severe $\mathrm{n}(\%)$ & & Low n (\%) & High n (\%) & \\
\hline Gender & & & & 1.000 & & & 0.446 & & & 0.296 \\
\hline Female & 16 & $7(43.8)$ & $9(56.3)$ & & $7(43.8)$ & $9(56.3)$ & & $11(68.8)$ & $5(31.3)$ & \\
\hline Male & 14 & $6(42.9)$ & $8(57.1)$ & & $4(28.6)$ & $10(71.4)$ & & $7(50.0)$ & $7(50.0)$ & \\
\hline Age (years) & & & & 0.306 & & & 0.433 & & & 0.143 \\
\hline Less than 21 & 5 & $4(80.0)$ & $1(20.0)$ & & $3(60.0)$ & $2(40.0)$ & & $5(100.0)$ & $0(0.0)$ & \\
\hline $21-30$ & 10 & $3(30.0)$ & $7(70.0)$ & & $3(30.0)$ & $7(70.0)$ & & $7(70.0)$ & $3(30.0)$ & \\
\hline 31.40 & 5 & $3(60.0)$ & $2(40.0)$ & & $3(60.0)$ & $2(40.0)$ & & $2(40.0)$ & $3(60.0)$ & \\
\hline $41-50$ & 6 & $2(33.3)$ & $4(66.7)$ & & $1(16.7)$ & $5(83.3)$ & & $3(50.0)$ & $3(50.0)$ & \\
\hline More than 50 & 4 & $1(25.0)$ & $3(75.0)$ & & $1(25.0)$ & $3(75.0)$ & & $1(25.0)$ & $3(75.0)$ & \\
\hline Educational attainment & & & & 0.318 & & & 0.214 & & & 0.794 \\
\hline Elementary school & 8 & $2(25.0)$ & $6(75.0)$ & & $1(12.5)$ & $7(87.5)$ & & $4(50.0)$ & $4(50.0)$ & \\
\hline Junior high school & 14 & $8(57.1)$ & $6(42.9)$ & & $7(50.0)$ & $7(50.0)$ & & $5(62.5)$ & $5(35.7)$ & \\
\hline Senior high school & 8 & $3(37.5)$ & $5(62.5)$ & & $3(37.5)$ & $5(62.5)$ & & $9(64.3)$ & $5(35.7)$ & \\
\hline AFB sputum result & & & & 1.000 & & & & & & 0.879 \\
\hline Negative & 18 & $8(44.4)$ & $10(55.6)$ & & 7 (38.9) & $11(61.1)$ & 1.000 & $11(61.1)$ & $7(38.9)$ & \\
\hline Positive & 12 & $5(41.7)$ & $7(58.3)$ & & $4(33.3)$ & $8(66.6)$ & & $7(58.3)$ & $5(41.7)$ & \\
\hline
\end{tabular}

AFB: acid-fast bacillus; MTB: Mycobacterium tuberculosis, TNF- $\alpha$ : tumor necrosis factor- $\alpha$

Table 4

The correlation between Mycobacterium tuberculosis lineage and lung damage.

\begin{tabular}{|c|c|c|c|c|c|}
\hline \multirow[t]{2}{*}{ Variable } & \multicolumn{2}{|l|}{ MTB lineage } & \multirow[t]{2}{*}{ Total } & \multirow[t]{2}{*}{ OR (CI 95\%) } & \multirow[t]{2}{*}{$p$-value } \\
\hline & Ancient (\%) & Modern (\%) & & & \\
\hline \multicolumn{6}{|c|}{ Lung damage } \\
\hline Mild & $10(90.9)$ & $1(9.1)$ & 11 & $3.97(1.57-6.37)$ & $<0.001$ \\
\hline Severe & $3(15.8)$ & $16(84.2)$ & 19 & & \\
\hline \multicolumn{6}{|l|}{ TNF- $\alpha$} \\
\hline Low & $11(61.1)$ & $7(38.9)$ & 18 & $2.06(1.31-47.00)$ & 0.026 \\
\hline Hight & $2(16.7)$ & $10(83.3)$ & 12 & & \\
\hline
\end{tabular}

MTB: Mycobacterium tuberculosis, OR: odds ratio, TNF- $\alpha$ : tumor necrosis factor-

NICE scoring system was employed to analyze pulmonary damage associated with MTB. This scoring system was initially developed to assess lung damage associated with $M$. avium not $M$. tuberculosis ${ }^{26}$.

\section{Conclusion}

Active pulmonary TB patients in Surabaya are predominantly infected with MTB modern lineage. This lineage is likely associated with higher TNF- $\alpha$ level and more severe lung tissue damage. In addition, patients with severe lung damage have higher level of TNF- $\alpha$ compared to those with mild lung damage cases.

\section{References}

1. WHO. Global. Tuberculosis Report. Geneva 2017; 2017. (Cited 2018 4.5); Available from:. www.who.int/tb/publications/global_report/en/.

2. WHO. Global. Tuberculosis Report. Geneva 2016; 2016. (Cited 2017 9.17); Available from:. www.who.int/tb/publications/global_report/en/.

3. Dheda K, Booth H, Hugget JF, Johnson MA, Zumla A, Rook GAW. Lung remodeling in pulmonary tuberculosis. J Infect Dis. 2005;192:1201-1210.

4. Forrellad MA, Kleep LI, Gioffre A, et al. Virulence factors of the Mycobacterium tuberculosis complex. Virulence. 2013;4(1):1-64.

5. Alexander KA, Laver PN, Michel AL, et al. Novel Mycobacterium tuberculosis complex pathogen, M. mungi. Emerg Infect Dis. 2010;16:1296-1299.

6. Coscolla M, Gagneux S. Consequences of genomic diversity in Mycobacterium tuberculosis. Semin Immunol. 2014;26:431-444.

7. Brosch R, Gordon SV, marmiesse M, et al. A new tuberculosis scenario for the Mycobacterium tuberculosis complex. Proc Nat I Acad Sci USA. 2002;99(6):3684-3689.

8. Gagneux S, Small PM. Global phylogeography of Mycobacterium tuberculosis and implications for tuberculosis product development. Lancet Infect Dis. 2007;7(5):328-337

9. Ravimoha S, Kornfeld H, Weissman D, Bisson GP. Tuberculosis and lung damage: from epidemiology to pathophysiology. Eur Respir Rev. 2018;27:1-20.

10. Tientcheu LD, Koch A, Ndengane M, Andosen G, Kampmann B, Wilkinson RS. Immunological consequences of strain variation within the Mycobacterium tuberculosis complex, Eur J Immumol. 2017:47:432-445.

11. Tsolaki AG, Gagneux S, Pym AS, et al. Genomic deletions classify the Beijing/W strains as a distinct genetic lineage of. $J$ Clin Microbiol. 2005;43:3185-3191.

12. Stavrum R, Praygood G, Range N, et al. Increased level of acute phase reactants in patients infected with modern Mycobacterium tuberculosis genotypes in Mwanza, Tanzania. BMC Infect Dis. 2014;14:309.

13. Dorhoi A, Kaufmann Stevan HE. Tumor necrosis factor alpha in mycobacterial infection. Semin Immunol, 2014:26:203-209.

14. Kindler V, Andre-Pascal Sappino, Grau GC, Piquet PF, Vassali P. The inducing role of tumor necrosis factor in the development of bactericidal granulomas during BCG infection. Cell. 1989;56:731-740.

15. Tsao TCY, Hong J, Huang C, Yang P, Liao SK, Chang KSS. Increased TNF-a, IL-1b and IL-6 levels in the bronchoalveolar lavage fluid with the upregulation of their mRNA in macrophages lavaged from patients with active pulmonary tuberculosis. Tuber Lung Dis. 1999:79(5):279-285.

16. De Andrade Junior DR, dos Santos SA, de Castro I, de Andrade DR. Correlation between serum tumor necrosis factor alpha levels and clinical severity tuberculosis. Braz J Infect Dis. 2008;12(3):226-233.

17. Manca C, Reed MB, Freeman S, et al. Differential monocyte activation underlies strain-specific Mycobacterium tuberculosis pathogenesis. Infect Immun. 2004;72(9):5511-5514.

18. Tanveer M, Hasan Z, Kanji A, Hussain R, Hasan R. Reduced TNF alpha and IFN responses to Central Asian strain 1 and Beijing isolates of Mycobacterium tuberculosis in comparison with H37Rv strain. Trans R Soc Trop Med Hyg. 2009;103:581-587.

19. Reed MB, Domenech P, manca C, et al. A glycolipid of hypervirulent tuberculosis strains that inhibits the innate immune response. Nature. 2004;431:84-87.

20. Portevin D, Gagneux S, Comas I, Young D. Human macrophage responses to clinical isolates from the Mycobacterium tuberculosis complex discriminate between Ancient and Modern lineages. PLoS Pathog. 2011:7(3):e1001307.

21. Sarkar R, Lenders L, Wilkinson KA, Wilkinson R.J, Nicol MP. Modern lineages of Mycobacterium tuberculosis exhibit lineage-specific patterns of growth and cytokine induction in human monocyte-derived macrophages. PLoS One. 2012;7(8):e43170.

22. Wang C, Peyron $\mathrm{P}$, Mestre $\mathrm{O}$, et al. Innate immune response to Mycobacterium tuberculosis Beijing and other genotypes. PLoS One. 2010;5(10):e13594.

23. Lasunskaia E, Ribeiro SCM, manichera O, et al. Emerging multidrug resistant Mycobacterium tuberculosis strains of the Beijing genotype circulating in Russia express a pattern of biological properties associated with enhanced virulence. Microb Infect. 2010;12(6):467-475.

24. Parsons LM, Brosch R, Cole ST, et al. Rapid and simple approach for identification of Mycobacterium tuberculosis complex isolates by PCR-based genomic deletion analysis. J Clin Microbiol. 2002;40(7):2339-2345.

25. Rieder HL, van Deun A, Kam KM, et al. Priorities for Tuberculosis Bacteriology Services in Low-income Countries. France: Norwegian Agency for Development Cooperation; 2007 (Norad).

26. Kurashima A, Morimoto K, Horibe M, Hoshino Y, Shiraishi Y, Kudoh S. A Method for visual scoring of pulmonary Mycobacterium avium complex disease: "NICE scoring system". Mycobact Dis. 2003;3(1):1-5.

27. Lewinshon DM, Leonard MK, LoBue PA, et al. Official American thoracic society/ infectious diseases society of America/centers for disease control and prevention clinical practice guidelines: diagnosis of tuberculosis in adults and children. Clin Infect Dis. 2017;64:111-115.

28. WHO. Xpert. MTB/RIF Implementation Manual: Technical and Operational 'how-to'; Practical Considerations, Geneva: WHO Press; 2014

29. WHO. Treatment. Of Tuberculosis Guideline, Geneva: WHO Press; 2018.

30. Parwati I, van Crevel R, Sudiro M, et al. Mycobacterium tuberculosis Population structures differ significantly on two Indonesian islands. $J$ Clin Microbiol. 2008;4(11):3639-3645.

31. Prakash O, Sharma R, Sehajpal PK. Predominance of modern Mycobacterium 
tuberculosis isolates in North India. Int $J$ Tuberc Lung Dis. 2014;18(2):196-197.

32. Asgharzadeh M, Kafil HS, Najati K, Ansarin K. Differentiation of modern and ancestral Mycobacterium tuberculosis in North west region of Iran by screening for the presence of TbD1. Afr J Microbiol Res. 2010;4(17):1856-1858.

33. Mokrousov I, Ly Ho M, Otten T, et al. Origin and primary dispersal of the Mycobacterium tuberculosis Beijing genotype: clues from human phylogeography. Genome Res. 2005;10:1357-1364.

34. Krishnan N, Malaga W, Constant $\mathrm{P}$, et al. Mycobacterium tuberculosis lineage influences innate immune response and virulence and is associated with distinct cell envelope lipid profiles. PLoS One. 2011;6(9):e23870.

35. De Jong BC, Hill PC, Brookes RH, et al. Mycobacterium africanum elicits an attenuated T cell response to early secreted antigenic target, $6 \mathrm{kDa}$, in patients with tuberculosis and their household contacts. $J$ Infect Dis. 2006;193:1279-1286.
36. Cole S, Brosch R, Parkhill J, et al. Deciphering the biology of Mycobacterium tuberculosis from the complete genome sequence. Nature. 1989;393:537-544. Mycobacterium bovis. PNAS. 2003;100(13):7877-7882

38. Korb VC, Chuturgoon AA, Moodley D. Mycobacterium tuberculosis: manipulator of protective immunity. Int J Mol Sci. 2016;17(131):2-15.

39. Malone KM, Gordon SV. Mycobacterium tuberculosis complex members adapted to wild and domestics animal. In: Gagneux S, ed. Strain Variation in the Mycobacterium tuberculosis Complex; its Role in Biology and Epidemiology and Control. Switzerland: Springer; 2017:135-154.

40. Gonzalo-Asensio J, Malaga W, Alexandre P, et al. Evolutionary history of tuberculosis shaped by conserved mutations in the PhoPR virulence regulator. Proc Nat I Acad Sci USA. 2014;111(31):11491-11496. 
The role of Mycobacterium tuberculosis lineages on lung tissue damage and TNF-a level among tuberculosis patients, Indonesia

ORIGINALITY REPORT

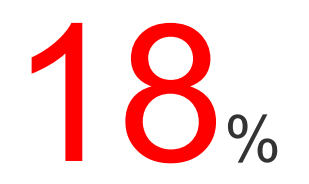

SIMILARITY INDEX
$13 \%$

INTERNET SOURCES
$15 \%$

PUBLICATIONS
$0 \%$

STUDENT PAPERS

\section{PRIMARY SOURCES}

1 "Strain Variation in the Mycobacterium tuberculosis Complex: Its Role in Biology,

Epidemiology and Control", Springer Science and Business Media LLC, 2017

Publication

2 academic.oup.com Internet Source

3 Harapan Harapan, Mudatsir Mudatsir, Rosaria Indah, Prattama S. Utomo et al. "Knowledge towards Zika among medical students, interns and general practitioners in Indonesia: A crosssectional study in Aceh", Clinical Epidemiology and Global Health, 2019

Publication

4 hal.archives-ouvertes.fr Internet Source 
7 Pallavi Sinha, Anamika Gupta, Pradyot Prakash,

Shampa Anupurba, Rajneesh Tripathi, G. N.

Srivastava. "Differentiation of Mycobacterium

tuberculosis complex from non-tubercular

mycobacteria by nested multiplex PCR targeting

IS6110, MTP40 and 32kD alpha antigen

encoding gene fragments", BMC Infectious

Diseases, 2016

Publication

8 www.johronline.com

Internet Source

9 link.springer.com

Internet Source

10 www.labome.org

11 Mohammad Hadi Dhegihan, Philip K. Hopke,

Farzaneh Baghal Asghari, Ali Akbar

Mohammadi, Mahmood Yousefi. "The effect of

the decreasing level of Urmia Lake on

particulate matter trends and attributed health

effects in Tabriz, Iran", Microchemical Journal,

2019

Publication 
13 journals.plos.org

Internet Source

14 WWW.science.gov

Internet Source

15 bmcpediatr.biomedcentral.com

Internet Source

16 www.paom.pl

Internet Source

17 socciweb.com.br

Internet Source

18 www.mdpi.com

Internet Source

19 "13th European Congress of Clinical

Microbiology and Infectious Diseases", Clinical

Microbiology and Infection, 2003

Publication

Shruthi Ravimohan, Hardy Kornfeld, Drew

Weissman, Gregory P. Bisson. "Tuberculosis

and lung damage: from epidemiology to

pathophysiology", European Respiratory

Review, 2018

Publication

Harapan Harapan, Samsul Anwar, Aslam 
21 Bustamam, Arsil Radiansyah et al. "Willingness to pay for a dengue vaccine and its associated determinants in Indonesia: A community-based, cross-sectional survey in Aceh", Acta Tropica, 2017

Publication

22 www.biomedcentral.com Internet Source

24 Farzad Khademi, Mohammad Derakhshan, Arshid Yousefi-Avarvand, Mohsen Tafaghodi,

Saman Soleimanpour. " Multi-stage subunit

vaccines against : an alternative to the BCG

vaccine or a BCG-prime boost? ", Expert

Review of Vaccines, 2017

Publication

Tsung-Hsien Lin, Hsueh-Wei Yen, Wen-Chol

Voon, Ho-Ming Su, Ye-Hsu Lu, Wen-Ter Lai,

Sheng-Hsiung Sheu. "Vascular endothelial

growth factor in coronary sinus: Evidence for its association with coronary collaterals",

Scandinavian Cardiovascular Journal, 2009

Publication

bmcresnotes.biomedcentral.com 
M. Arifin Parenrengi, Fatkhul Adhiatmadja,

Muhammad Reza Arifianto, Tedy Apriawan,

Asra Al Fauzi, Franco Servadei. "Bilateral skull

fracture with massive epidural hematoma

secondary to pin-type head fixation in a pediatric

patient: Case report and review of the literature",

International Journal of Surgery Case Reports,

2019

Publication

28

29

Pramod K Giri, Gopal K Khuller. "Is intranasal

vaccination a feasible solution for

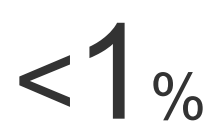

tuberculosis?", Expert Review of Vaccines, 2014

Publication

Sebastien Gagneux. "Host-pathogen

coevolution in human tuberculosis",

$<1 \%$

Philosophical Transactions of the Royal Society

B: Biological Sciences, 2012

Publication

Jones-López, Edward C., Soyeon Kim, Geisa

Fregona, Patricia Marques-Rodrigues, David

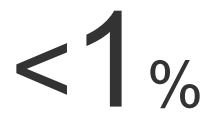

Jamil Hadad, Lucilia Pereira Dutra Molina,

Solange Vinhas, Nancy Reilly, Stephanie Moine,

Soumitesh Chakravorty, Mary Gaeddert,

Rodrigo Ribeiro-Rodrigues, Padmini Salgame,

Moises Palaci, David Alland, Jerrold J. Ellner,

and Reynaldo Dietze. "Importance of Cough

and M. tuberculosis Strain Type as Risks for 
Increased Transmission within Households",

PLoS ONE, 2014.

Publication

31 oro.open.ac.uk

Internet Source

$<1 \%$

32 www.chestjournal.org

Internet Source

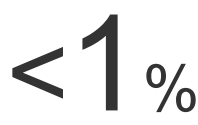

33 Jotam G. Pasipanodya, Patrick K. Moonan,

Edgar Vecino, Thaddeus L. Miller et al.

"Allopatric tuberculosis host-pathogen

relationships are associated with greater

pulmonary impairment", Infection, Genetics and

Evolution, 2013

Publication

34

K. Furuuchi, A. Ito, T. Hashimoto, S. Kumagai,

T. Ishida. " Clinical significance of the

radiological severity score in complex lung

disease patients ", The International Journal of

Tuberculosis and Lung Disease, 2017

Publication

35

"Pharmacology of Immunotherapeutic Drugs",

Springer Science and Business Media LLC,

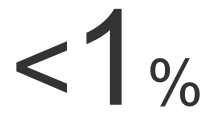

2020

Publication

Harapan, Harapan, Samsul Anwar, Abdul Malik

Setiawan, and R. Tedjo Sasmono. "Dengue

vaccine acceptance and associated factors in 
Indonesia: A community-based cross-sectional

survey in Aceh", Vaccine, 2016.

Publication

37 bekircakir.com

Internet Source

38 en.mercopress.com

39 Liliana K. Rutaihwa, Mohamed Sasamalo,

Aladino Jaleco, Jerry Hella et al. "Insights into the genetic diversity of Mycobacterium tuberculosis in Tanzania", PLOS ONE, 2019

Publication

40

Qama, Diana, Won-Il Choi, and Kun Kwon.

"Immune responses in the lungs of patients with tuberculous pleural effusion without pulmonary tuberculosis", BMC Immunology, 2012.

Publication

Exclude quotes

Exclude bibliography
On

On
Exclude matches

Off 


\section{The role of Mycobacterium tuberculosis lineages on lung tissue damage and TNF-a level among tuberculosis patients, Indonesia}

FINAL GRADE

$/ 100$

PAGE 1

PAGE 2

PAGE 3

PAGE 4

PAGE 5
GENERAL COMMENTS

Instructor 